\title{
How Exogenous Selenium Affects Anthocyanin Accumulation and Biosynthesis-Related Gene Expression in Purple Lettuce
}

\author{
Dandan Liu, Hui Li, Yongzhu Wang, Zhengzheng Ying, Zhiwei Bian, \\ Wenli Zhu, Wei Liu, Lifei Yang*, Dahua Jiang \\ College of Horticulture, Nanjing Agricultural University, Nanjing 210095, China
}

Received: 12 September 2016

Accepted: 3 November 2016

\begin{abstract}
We studied the effects of selenite on growth and anthocyanin accumulation in purple lettuce. The results will ascertain which selenite concentration is more advantageous to the purple lettuce and help study the effect of selenite on the molecular mechanism of plant anthocyanin accumulation using the quantitative reverse transcription polymerase chain reaction (qRT-PCR). In this study, the low selenite concentrations $(\leq 8 \mu \mathrm{M})$ could not only promote purple lettuce growth including plant height, leaf area (LA), and fresh weight (FW), but also the anthocyanin contents which may be due to how the selenite affects the UDPglycose flavonoid glycosyl transferase (UFGT) and flavanone 3-hydroxylase (F3H) genes expression of anthocyanin biosynthesis. Next, on the basis of the obtained results from the preliminary experiments, $8 \mu \mathrm{M}$ selenite was used to analyze the anthocyanin accumulation with the treatment time prolonged. Although the anthocyanin content of purple lettuce was not reduced on day 24 , the control plants were significantly decreased. The reason may be that compared with the control plants, UFGT and F3H genes were markedly up-regulated on day 24 . Therefore, the influence of selenium on anthocyanin accumulation and molecular regulation of anthocyanin synthesis is mainly due to the expression levels of the $\mathrm{F} 3 \mathrm{H}$ and UFGT gene. It needs to be a further studied.
\end{abstract}

Keywords: purple lettuce, selenite, anthocyanin, gene expression

\section{Introduction}

Anthocyanins are natural water-soluble red, orange, purple, or blue pigments found in fruits and vegetables and that belong to the flavonoid polyphenol compounds [1]. Anthocyanins are deemed natural food additives in the food industry [2] because they not only have many

*e-mail: lfy@njau.edu.cn benefits for plants, such as promoting pollination and seed dispersal and protecting against different biotic and abiotic stresses [3-4], but also on human health and wellbeing due to their antioxidant properties and free radical scavenging capacity, which can protect people against cardiovascular disease, coronary heart disease, and cancer [5-7].

The accumulation of anthocyanins is controlled by such genetic and environmental factors as temperature stress, light, irrigation, and so on [8-9], as well as the expression of structural and regulatory genes in the anthocyanin 
biosynthesis pathway [10]. In recent years, many studies have reported the molecular regulation of anthocyanin biosynthesis in response to different grown environments. Larbat reported that the structural genes of phenylalanine ammonialyase (PAL), chalcone synthase (CHS), and flavanone 3-hydroxylase $(\mathrm{F} 3 \mathrm{H})$ significantly increased in answer to nitrogen $(\mathrm{N})$ depletion [11]. Many studies found that the expression of the UDP-glycose flavonoid glycosyl transferase (UFGT) gene is vital to anthocyanin accumulation in many plants, including strawberry, lychee, and grape [12-13]. Although anthocyanin biosynthesis has been extensively studied in many plants, there is still a dearth of knowledge on the expression of anthocyanin biosynthetic genes to Se supplement, especially in lettuce. In this study, four genes (including CHS, F3H, F3' H, and UFGT) were selected to explore the influence of Se on the molecular mechanism of anthocyanin biosynthesis.

Selenium (Se) is a necessary trace element for the human body that can improve the body's immune system and reduce cancer risk in a moderate amount of selenium content. Selenocysteine (SeCys) is considered to be the 21 st amino acid, which is the main component of a variety of antioxidant enzymes and is located in the protease's active site [14]. Therefore, Se has important significance in terms of increasing resistance of plants and animals. Increasing Se content in the diet is an effective method to solve Se deficiencies in plants and animals [15]. Se in the soil can be incorporated into the food chain mainly via crops. Recent years have seen a lot of research about Seenriched plants. Nevertheless, the scope of Se deficiency and Se toxicity in plants is very narrow. Hence, it is of great importance to ascertain the best Se concentration in the process of Se-enriched production plants.

Lettuce (Lactuca sativa L.) is not only one of the most widely consumed leaf vegetables in the world, but it also provides a high nutritional value, such as anthocyanin and vitamins $\mathrm{A}, \mathrm{C}$, and $\mathrm{E}$ - particularly in purple lettuce. However, to date there have been no reports about the specific response of purple lettuce physiology and anthocyanin biosynthetic genes to Se. Thus, the aim was to evaluate the physiological response of purple lettuce (Lactuca sativa L.) cv. 'Purple Rome' to different $\mathrm{Se}$ concentrations $(0,4,8,12,16 \mu \mathrm{M})$ in the form of selenite added into the hydroponic systems, and explore the effect of selenite on anthocyanin accumulation.

\section{Materials and Methods}

\section{Plant Culture}

In September 2015 we conducted a study in the greenhouse of Nanjing Agricultural University. The purple lettuce seeds (Lactuca sativa), 'Purple Rome,' were soaked in tap water for eight to 12 hours at 25 to $30^{\circ} \mathrm{C}$ and then transferred to a tray with composite substrates containing perlite, vermiculite, and sphagnum peat moss (1:1:2, $\mathrm{w} / \mathrm{w})$, germinated at $25^{\circ} \mathrm{C}$ for 15 to 18 days and watered every day. As soon as cotyledons emerged, the seedlings were transferred to the tray. At the four-leaf stage, the seedlings were removed to the holes of styrofoam slabs in the hydroponic system of NFT filling with 1/2 Hoagland nutrient solution [16]. Afterward, the nutrient solution was changed every three days. The plants were cultured under the following conditions: $25 / 22^{\circ} \mathrm{C}, 14 \mathrm{~h} / 10 \mathrm{~h}$ (day/night), relative humidity of $60-70 \%$, and supplemental oxygen for $30 \mathrm{~min}$ every $6 \mathrm{~h}$.

\section{Se Treatment}

There were three replicates with six plants per replicate in each treatment. The different treatments, including selenite $\left(0,4,8,12\right.$, and $16 \mu \mathrm{M}$ as $\left.\mathrm{Na}_{2} \mathrm{SeO}_{3}\right)$ at the basis of the previous work [17], were carried out along with renewing the solution starting from the six-leaf stage and ending five days before taking the samples (the $30^{\text {th }}$ day after treatment). We went on the second experiment on the basis of our previous work, which confirmed that $8 \mu \mathrm{M}$ $\mathrm{Na}_{2} \mathrm{SeO}_{3}$ was most beneficial to the purple lettuce growth and anthocyanin accumulation. Therefore, two treatments $(0$ and $8 \mu \mathrm{M})$ were set to explore the effect of selenite on the expression of anthocyanin biosynthetic genes using the real time quantitative PCR (qRT-PCR). The samples were taken from days $3,6,9.12,15,18,21$, and 24 in the same place of purple lettuce after selenite treatment, separately.

\section{Analysis of the Plant Height, Fresh Weight, Dry Weight, Water Content and Leaf Area}

The purple lettuce samples were taken from the third leaf in the outside and rinsed three times in deionized water to remove any external selenite. Simultaneously, each treatment chose three plants randomly to measure plant height, fresh weight (FW), dry weight (DW), water content (WC), and leaf area (LA). The plant leaves were dried at $60^{\circ} \mathrm{C}$ in a drying oven until constant mass as DW. The water content was calculated as the formula: $\mathrm{WC}(\%)=(\mathrm{FW}-\mathrm{DW}) / \mathrm{FW} \times 100 \%$. The leaf area was determined using a CI-202 laser area meter (CID BioScience, USA) and expressed in square centimeters $\left(\mathrm{cm}^{2}\right)$.

\section{Se Content}

The samples were obtained in a manner similar to determining the Se content via undergoing mineralization at $65 \%$ super pure $\mathrm{HNO}_{3}$ in a CEM MARS-5 Xpress microwave oven. Selenium concentrations by hydride atomic fluorescence spectrometry, and finally calculated the selenium content in the plant sample [18].

\section{Determining Anthocyanin Content}

The method of anthocyanin extraction was as follows: 400 milligram fresh leaves were soaked in $12 \mathrm{ml}$ of critic acid-sodium citrate buffer solution. They were shocked at $50^{\circ} \mathrm{C}$ for $1 \mathrm{~h}$, which was the appropriate condition 
to obtain maximum extraction capacity. And then the extraction was centrifuged at $4,000 \mathrm{rpm} / \mathrm{min}$ at $4^{\circ} \mathrm{C}$ for $10 \mathrm{~min}$ with centrifuge. Anthocyanin was determined by the $\mathrm{pH}$ differential method [19]. The results were shown as milligrams of cyanidin-3-glucoside (Cy-3-Glu) equivalents per gram of fresh weight.

\section{RNA Extraction and the Real Time Quantitative PCR (qRT-PCR) Analysis}

We analyzed the relative expression level of the four genes involved in the anthocyanin biosynthetic by using qRT-PCR to study the effect of the selenite on anthocyanin accumulation (Table 1). Total RNA was extracted from the purple lettuce leaves by utilizing TRIzol Reagent (Life Technologies, Carlsbad, CA, USA) according to the manufacturer's instructions. The first cDNA strand was synthesized using the PrimeScript RT reagent kit (TaKaRa, Kyoto, Japan) using $1 \mu \mathrm{g}$ of total RNA pretreated with DNaseI (TaKaRa) to eliminate the contaminating genomic DNA. The qRT-PCR was executed on an MX3005p QPCR System (Agilent Technologies, Santa Clara, CA, USA) using SYBR Premix Ex TaqTM II (TaKaRa). The amplification procedure was as follows: $95^{\circ} \mathrm{C}$ for $30 \mathrm{~s}, 40$ cycles of $95^{\circ} \mathrm{C}$ for $5 \mathrm{~s}$, and $60^{\circ} \mathrm{C}$ for $20 \mathrm{~s}$. Reactions were performed with three biological replicates and two technical replicates. All qRT-PCR reactions were normalized using the actin gene. The relative gene expression levels were calculated using the method of $2^{-\Delta \Delta \mathrm{CT}}[20]$.

\section{Statistical Analysis}

The data obtained from the experiment were dissected utilizing two methods. The data were subjected to analysis of variance (ANOVA) at 95\% confidence. Furthermore, Turkey's multiple range test was used in order to estimate the significance of differences between average values. Graphs were drawn using Microsoft Excel software.

Table 1. Primer sequences used for qRT-PCR analysis.

\begin{tabular}{|c|c|c|}
\hline Gene & $\mathrm{F} / \mathrm{R}$ & Primer sequence $\left(5^{\prime}-3^{\prime}\right)$ \\
\hline CHS & $\mathrm{F}$ & GGTTTGCTCTGAGATTACAG \\
\hline & $\mathrm{R}$ & TCCTTGAGACCAAGCTTGAG \\
\hline$F 3 H$ & $\mathrm{~F}$ & AAGCGACTCGTGATGGTGG \\
\hline & $\mathrm{R}$ & GCCTGGTGATCCGCATTCT \\
\hline F3'H & $\mathrm{F}$ & GAATGGGCAATAGCGGAACT \\
\hline & $\mathrm{R}$ & AGCCTAAAGGTTTCCTTCACAATGG \\
\hline UFGT & $\mathrm{F}$ & TGGAGAAGCGGGTTAGACAGTTGATGGA \\
\hline Actin & $\mathrm{R}$ & TATAGCTACCATGATTCAACCAACTTCG \\
\hline & $\mathrm{R}$ & GCAACTGGGATGACATGGAAA \\
\hline
\end{tabular}

F: Forward primer; R: Reverse primer a)

b)
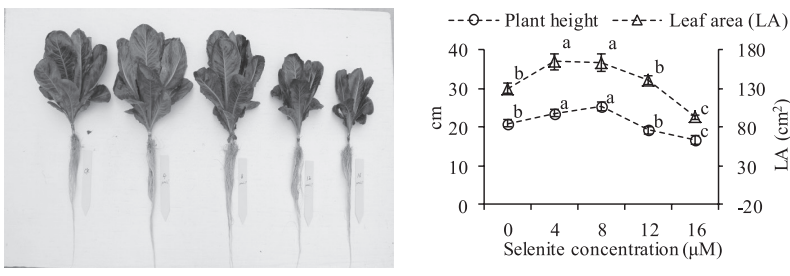

Fig. 1. Influence of introduction to the nutrient solution of selenite on purple lettuce growth a) and plant height and leaf area b). Mean values marked with the different letters are significantly different $(\mathrm{p}<0.05)$ by Turkey's multiple comparison test. The values are mean $\pm \mathrm{SD}(\mathrm{n}=3)$.

\section{Results}

\section{Plant Height and Leaf Area}

Fig. 1a) clearly shows the changes about the purple lettuce under selenite treatments. Compared with control plants, the different selenite treatments had a significant effect on plant height and leaf area, which both reached a maximum in the presence of $8 \mu \mathrm{M}$ selenite and then dropped rapidly (Fig. 1b). However, there was no significant difference in 4 and $8 \mu \mathrm{M}$. At $16 \mu \mathrm{M}$, both plant height and the leaf area were lower than that of the control plants.

\section{Fresh Weight, Dry Weight and Water Content}

Under the treatment of selenite, both the FW and WC significantly increased immediately at $4 \mu \mathrm{M}$ and then dropped, but they did not reach a significant level between $4 \mu \mathrm{M}$ and $8 \mu \mathrm{M}$ (Fig. 2). The water content was only lower than the control plant at $16 \mu \mathrm{M}$. In comparison to the control, DW can be maintained in a stable level at

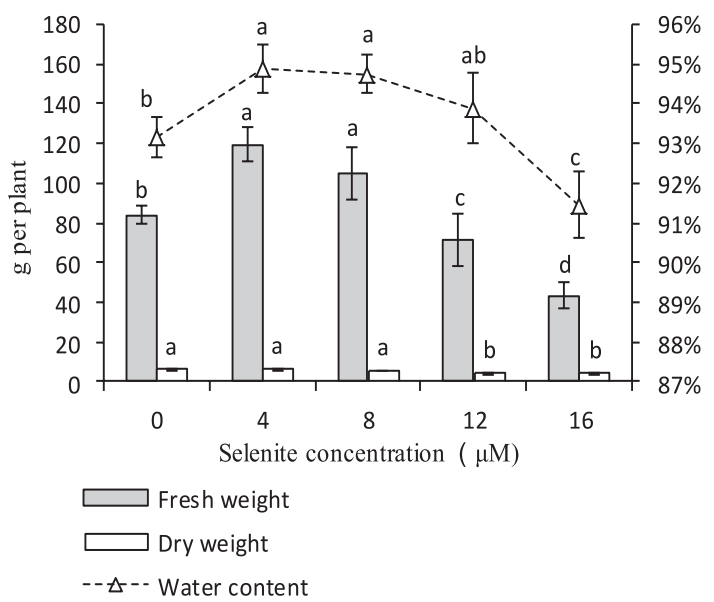

Fig. 2. Effects of increased selenite concentrations in the nutrient solution on fresh weight, dry weight and water content of the purple lettuce leaves. Mean values marked with the different letters are significantly different $(p<0.05)$ by Turkey's multiple comparison test. The values are mean $\pm \mathrm{SD}(\mathrm{n}=3)$. 


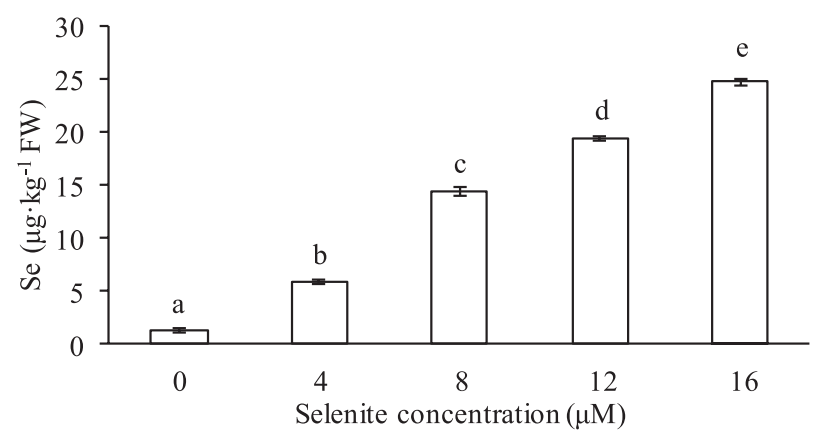

Fig. 3. Effects of increased selenite concentrations in the nutrient solution on the Se concentrations in purple lettuce leaves. Mean values marked with the different letters are significantly different $(\mathrm{p}<0.05)$ by Turkey's multiple comparison test. The values are mean $\pm \mathrm{SD}(\mathrm{n}=3)$.

low selenite concentration $(\leq 8 \mu \mathrm{M})$. However, both the FW and DW were noted for significant decreases when selenite concentrations exceeded $8 \mu \mathrm{M}$ and were lower than the control.

\section{Se Content}

As shown in Fig. 3, we observed a significant increase in Se content of the purple lettuce leaves by in-creasing the selenite concentration in the nutrient solution. Se content reached the maximum at the concentration of $16 \mu \mathrm{M}$. Nevertheless, we found maximum growth percentage at the low concentration. That is to say, the Se contents of the purple lettuce leaves with each rise in the selenite concentration were continuous in general, whereas the growth rate gradually decreased.

\section{Anthocyanin Content}

Fig. 4 shows anthocyanin content in the purple lettuce leaves after the different treatments with selenite. A significant increase was noted in pace with the selenite concentration increased compared with the control.

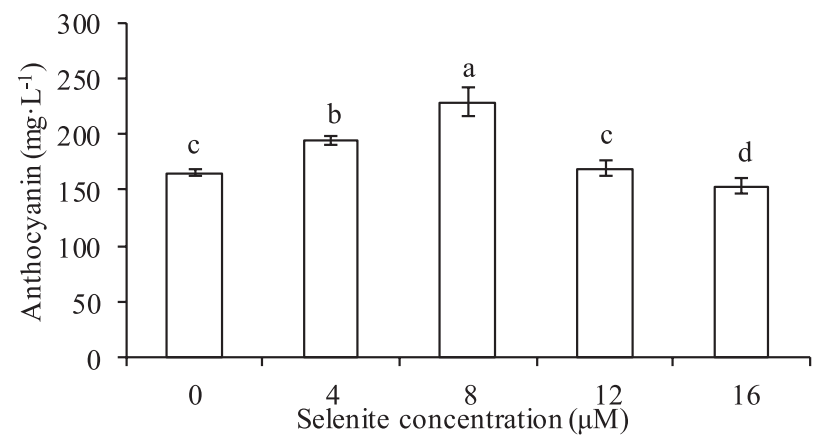

Fig.4. Effects of increased selenite concentrations in the nutrient solution on the anthocyanin concentrations in purple lettuce leaves. Mean values marked with the different letters are significantly different $(\mathrm{p}<0.05)$ by Turkey's multiple comparison test. The values are mean $\pm \mathrm{SD}(\mathrm{n}=3)$.

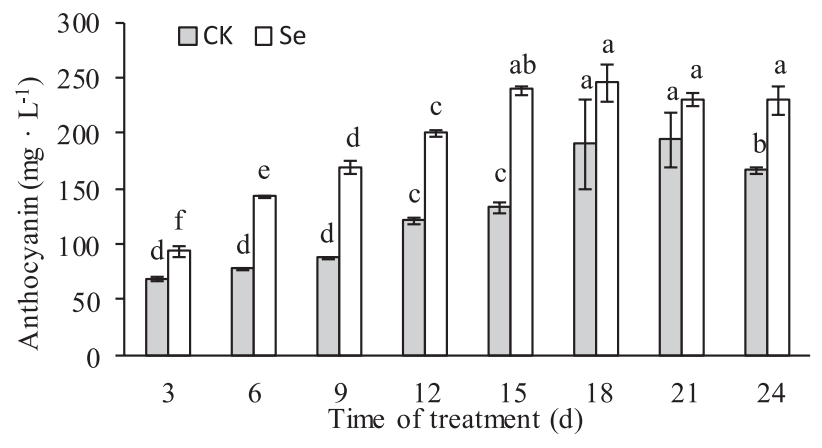

Fig. 5. Effects of selenite on the anthocyanin concentrations in the purple lettuce leaves after different time of treatment. Mean values marked with the different letters are significantly different $(p<0.05)$ by Turkey's multiple comparison test. The values are mean $\pm \mathrm{SD}(\mathrm{n}=3)$.

Furthermore, the greatest increase of anthocyanin content was found at a rate of $8 \mu \mathrm{M}$ by about $38.8 \%$.

\section{Effect of Selenite on Anthocyanin Content in Different Times of Treatment}

The anthocyanin contents of purple lettuce cultured in the nutrient solution with selenite were all higher than the control (Fig. 5). With the treatment time prolonged, the anthocyanin contents continued to increase significantly. However, the control plants did not find significant difference in the first nine days of the growth period. It was noted that the maximum appeared on day 15 after selenite treatment and then kept a plateau, whereas anthocyanin content in the control plants appeared at maximum on day 18 , and showed a significant decrease on day 24 of the growth period.

\section{Effect of Selenite on the Expression of Anthocyanin Biosynthetic Genes}

Four genes were designed to analyze the effect of the different selenite treatments on anthocyanin accumulation (Fig. 6). The relative expression level of the $\mathrm{CHS}$ and $\mathrm{F3}^{\prime} \mathrm{H}$ genes in the purple lettuce leaves were both significantly higher than the control, and reached the maximum in the presence of $16 \mu \mathrm{M}$, which was up-regulated about 364and 6-fold, respectively, compared with the control. The $\mathrm{F} 3 \mathrm{H}$ gene was not affected by the selenite supplemented in addition to the selenite concentration of $8 \mu \mathrm{M}$. The $U F G T$ gene was significantly down-regulated except for $8 \mu \mathrm{M}$. The expression level of the $F 3 H$ and $U F G T$ genes obtained the maximum at the rate of $8 \mu \mathrm{M}$ (by about 1.8and 30.6-fold).

\section{Effect of Selenite on the Expression of Anthocyanin Biosynthetic Genes in Different Times of Treatment}

The relative expression level of $C H S$ and $F 3^{\prime} H$ genes were similar (Fig. 7). When the nutrient solution was 
a)

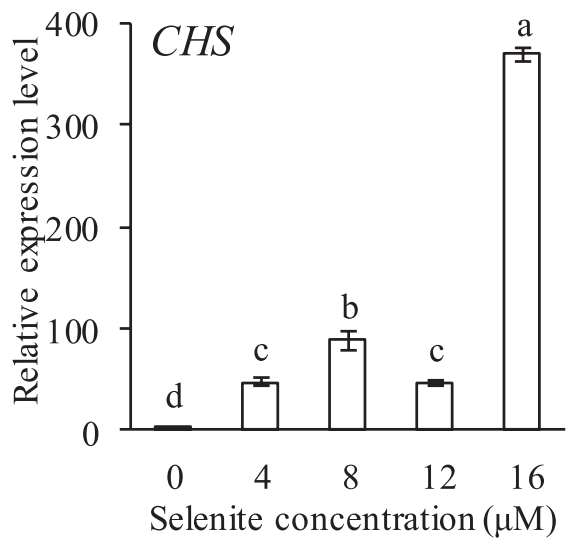

b)

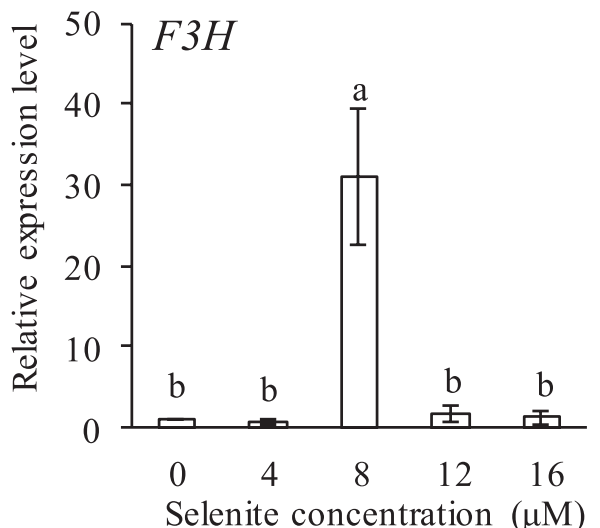

c)

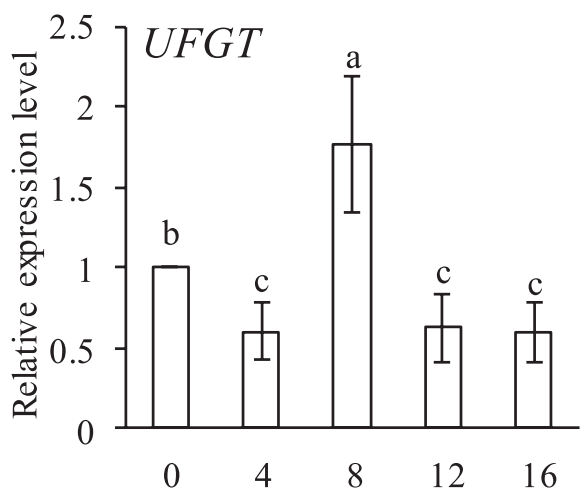

Selenite concentration $(\mu \mathrm{M})$

d)

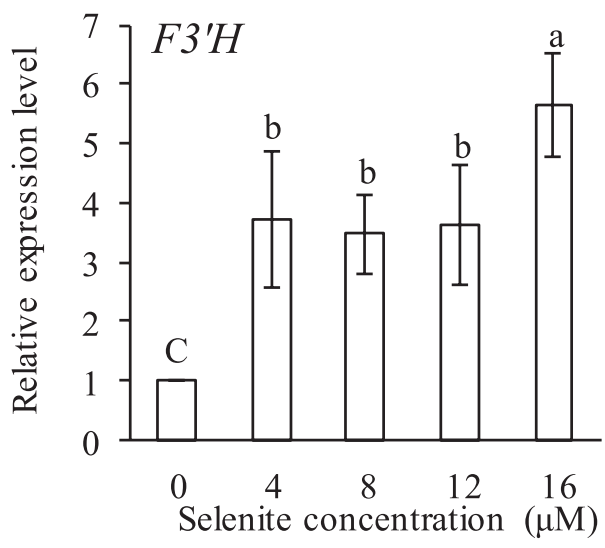

Fig.6. Effects of selenite on the expression analysis of anthocyanin biosynthetic genes in the purple lettuce leaves. Mean values marked with the different letters are significantly different $(p<0.05)$ by Turkey's multiple comparison test. The values are mean $\pm \operatorname{SD}(n=3)$. supplied with selenite, both the $C H S$ and $F 3^{\prime} H$ genes appeared in two peaks (on days 9 and 15) during the growth period. Moreover, the $C H S$ gene was higher than that of the control plants except on day 12. However, there was just one peak on days 9 ( $C H S$ gene) and $15\left(F 3^{\prime} H\right.$ gene) in the plants grown without selenite addition. After selenite treatment, the expression of $F 3 H$ gene was lower than that of control plants apart from days 21 and 24 . Moreover, compared with the control, there were three peaks in the period of growth. The three peaks were on
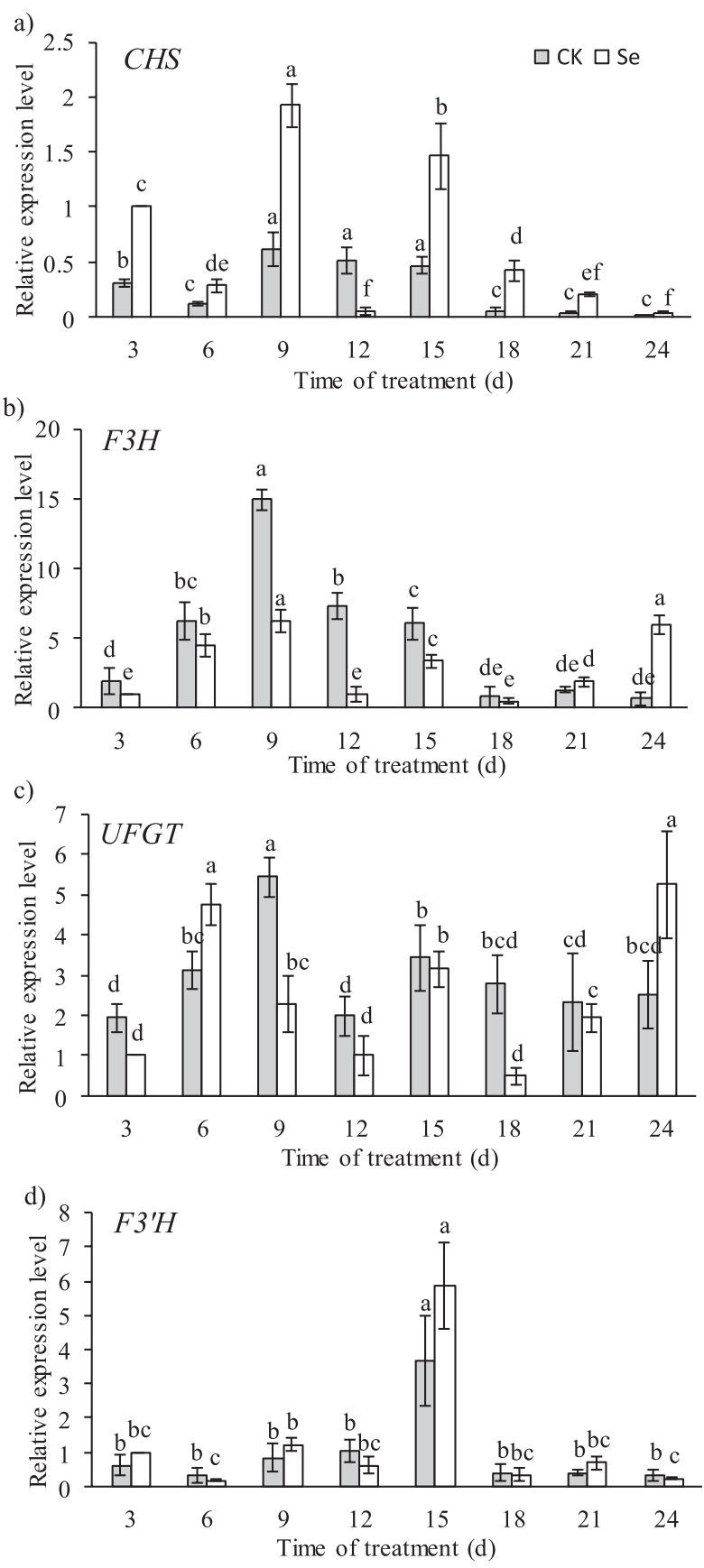

Fig.7. Effects of selenite on the expression analysis of anthocyanin biosynthetic genes in the purple lettuce leaves after different time of treatment. Mean values marked with the different letters are significantly different $(p<0.05)$ by Turkey's multiple comparison test. The values are mean $\pm \mathrm{SD}(\mathrm{n}=3)$. 
days 9,15 , and 24, separately; whereas the control plants had only two peaks (days 9 and 21). Compared with the plants grown without selenite addition, under selenite treatment the peaks of the UFGT gene expression level in the plants appeared from days 6,15 , and 24 . The maximum was found in the third peak, namely on day 24 , and was significantly higher than control.

\section{Discussion}

Selenium is not only essential for normal growth and development of plants, but also necessary for animals, humans, and some microbes [21]. Hamilton reported that proper Se concentrations can keep the body functions in a stable state, whereas high concentrations of Se will have toxic effects. Anthocyanin has many physiological effects on plants and humans, such as antioxidation, antisenity, protection against ultraviolet damage, and the prevention and treatment of various diseases [22]. However, little research reports which concentration of selenite does not merely enrich Se but also accumulates anthocyanin in order to achieve the dual purpose of Se and anthocyanin enrichment in purple lettuce. In this study, we can clearly note that selenite could promote purple lettuce growth at low concentrations, but purple lettuce growth was inhibited at high concentrations (exceeding $8 \mu \mathrm{M}$ ) as compared with the control (Figs 1 and 2). With the increase of selenite concentration in the nutrient solution, Se content in agricultural plants significantly increased, which agrees with those previous results [2325].

Based on our previous research, we identified $8 \mu \mathrm{M}$ selenite as the best concentration used for Se biofortification in purple lettuce. In this study, the results indicated that when $8 \mu \mathrm{M}$ selenite is added to the nutrient solution, the anthocyanin contents of the purple lettuce leaves reached the maximum, and appeared to peak on the 15th day after selenite treatment, while the control plants were up to the maximum on day 18 . However, we noted a significant reduction on day 24 , which may be due to the fact that selenite can promote the related enzyme activities in the anthocyanin biosynthesis, thus inhibiting the degradation of anthocyanin at a later stage of growth.

Many studies have shown that anthocyanin content of fruits and vegetables is closely related to the gene expression of the enzyme in anthocyanin biosynthesis pathways [2627]. The genes of anthocyanin biosynthesis include the structural gene ( PAL, CHS, F3H, F3'H, ANS, DFR, and UFGT) [28] and the transcription factor (MYB, bHLH, and WD40) [29]. Anthocyanin accumulation in the leaves of purple yam chimed with a trend in PAL, F3H, ANS, and UFGT gene expression [30]. Povero transformed the Aft and Atv genes into the tomato, found that anthocyanin content increased, and that $\mathrm{CHS}, \mathrm{F} 3 \mathrm{H}, \mathrm{F} 3{ }^{\prime} \mathrm{H}$, DFR, ANS, and UFGT genes expressions were all up-regulated, and eventually obtained a purple tomato [31]. The results of this study showed that under the different concentrations of selenite, the CHS and F3'H genes were significantly up-regulated in low concentrations, which is coincident with the results of Tsuda [32]. These reports make it clear that the CHS and F3'H genes were absolutely the key gene to anthocyanin synthesis related to the accumulation of anthocyanin. Moreover, the F3H and UFGT genes reached the maximum and significantly up-regulated by only $8 \mu \mathrm{M}$ compared to the control. Therefore, we can infer that the selenite affecting anthocyanin accumulation of the purple lettuce may be due to F3H and UFGT gene expression. On the other side, the relationship between selenite and anthocyanin content as well as the gene expression levels of anthocyanin biosynthesis in the different times after selenite treatment were not reported in other studies. In this experiment, as the treatment time of selenite prolonged, the reason why the anthocyanin content of purple lettuce on day 24 didn't reduce, yet the control plant significantly decreased due to the significant expression of $\mathrm{F} 3 \mathrm{H}$ and UFGT genes on day 24 compared with control.

All in all, how the F3H and UFGT genes affect the molecular mechanism of anthocyanin accumulation should be further studied. The results of this study have an important guiding significance to determining what time to harvest the Se-rich purple lettuce.

\section{Conclusions}

Se accumulation in plant species can affect growth. In the current study, low selenium concentration promotes plant growth. This study confirms that low levels of selenium can promote the accumulation of anthocyanin in lettuce. For $\mathrm{Na}_{2} \mathrm{SeO}_{3}$ treated with different concentrations compared with the control, with the selenium concentration, purple lettuce anthocyanin content increased, reaching a maximum at $8 \mu \mathrm{M}$ place. qRT-PCR analysis showed that low concentrations of Se can promote the accumulation of anthocyanin, and that maybe the $\mathrm{F} 3 \mathrm{H}$ and UFGT genes play a key role. In-depth study of the molecular mechanism of anthocyanin biosynthesis for developing rich anthocyanin food meets the growing demand for good health food being of great significance.

\section{Acknowledgements}

This study was financially supported by the National Natural Science Foundation of China (No. 31401857), the Fundamental Research Funds for the Central Universities (No. KJQN201543), and the Priority Academic Program Development of Jiangsu Higher Education Institutions (2014PAPD) of China.

\section{References}

1. HARBORNE J.B., WILLIAMS C.A. Advances in flavonoid research since 1992. Phytochemistry. 55 (6), 481, 2000.

2. SHIPP J., ABDELAAL E.M. Food applications and physiological effects of anthocyanins as functional food ingredients. Open Food Science Journal. 4 (1), 7, 2010. 
3. ALLAN A.C., HELLENS R.P., LAING W.A. MYB transcription factors that colour our fruit. Trends in Plant Science. 13 (3), 99, 2008.

4. ROWAN D.D., CAO M., LIN-WANG K., COONEY J.M., JENSEN D.J., AUSTIN P.T. Environmental regulation of leaf colour in red 35S:PAP1 Arabidopsis thaliana. New Phytologist. 182 (1), 102, 2009.

5. RIO D.D., RODRIGUEZ-MATEOS A., SPENCER J.P.E., TOGNOLINI M., BORGES G., CROZIER A. Dietary (poly) phenolics in human health: structures, bioavailability, and evidence of protective effects against chronic diseases. Antioxidants \& Redox Signaling. 18 (14), 1818, 2013.

6. HE J., GIUSTI M.M. Anthocyanins: natural colorants with health-promoting properties. Annual Review of Food Science \& Technology. 1 (3), 163, 2010.

7. ZHANG J., LAZARENKO O.P., BLACKBURN M.L., BADGER T.M., RONIS M.J.J., CHEN J.R. Blueberry consumption prevents loss of collagen in bone matrix and inhibits senescence pathways in osteoblastic cells. Age. $\mathbf{3 5}$ (3), 807, 2013

8. NASCIMENTO L.B.S., LEAL-COSTA M.V., COUTINHO M.A.S., MOREIRA N.D.S., LAGE C.L.S., BARBI N.D.S. Increased Antioxidant Activity and Changes in Phenolic Profile of Kalanchoe pinnata, (Lamarck) Persoon (Crassulaceae) Specimens Grown Under Supplemental Blue Light. Photochemistry \& Photobiology. 89 (2), 391, 2013.

9. ZHANG C., JIA H., WU W., WANG X., FANG J., WANG C. Functional conservation analysis and expression modes of grape anthocyanin synthesis genes responsive to low temperature stress. Gene. 574 (1), 168, 2015.

10. JAAKOLA L. New insights into the regulation of anthocyanin biosynthesis in fruits. Trends in Plant Science. 18 (9), 477, 2013.

11. LARBAT R., OLSEN K.M., SLIMESTAD R., LØVDAL T., BÉNARD C., VERHEUL M. Influence of repeated shortterm nitrogen limitations on leaf phenolics metabolism in tomato. Phytochemistry. 77 (1), 119, 2012.

12. GRIESSER M., SCHWAB W. Redirection of flavonoid biosynthesis through the down-regulation of an anthocyanidin glucosyltransferase in ripening strawberry fruit. Plant Physiology. 146 (4), 1528, 2008.

13. ZHAO Z.C., HU G.B., HU F.C. The UDP glucose: flavonoid3-O-glucosyltransferase (UFGT) gene regulates anthocyanin biosynthesis in litchi (Litchi chinesis, Sonn.) during fruit coloration. Molecular Biology Reports. 39 (6), 6409, 2012.

14. O'DELL B.L., SUNDE R.A. Handbook of nutritionally essential mineral elements. Handbook of Nutritionally Essential Mineral Elements. 1997.

15. L. GARCIABANUELOS M., A. HERMOSILLOCERECERES M., SANCHEZ E. The Importance of Selenium Biofortification in Food Crops. Current Nutrition \& Food Science. 7 (3), 181, 2011.

16. HOAGLAND D.R., ARNON D.I. The water-culture method for growing plants without soil. Calif.agric.exp.stn.circ. 347 (5406), 357, 1950.

17. HAWRYLAK-NOWAK B. Comparative effects of selenite and selenate on growth and selenium accumulation in lettuce plants under hydroponic conditions. Plant Growth Regulation. 70 (2), 149, 2013.
18. MIGASZEWSKI Z.M. The Quality of Element Determinations in Plant Materials by Instrumental Methods. Polish Journal of Environmental Studies. 15 (2), 154, 2006.

19. GIUSTI M.M., WROLSTAD R.E. Characterization and Measurement of Anthocyanins by UV-Visible Spectroscopy. Current Protocols in Food Analytical Chemistry. 63, 2001.

20. LIVAK K.J., SCHMITTGEN T.D. Analysis of Relative Gene Expression Data Using Real-Time Quantitative PCR and the $2^{-\triangle \Delta C T}$ Method. Methods. 25 (4), 402, 2001.

21. GERM M., STIBILJ V., KREFT I., GERM M. Metabolic Importance of Selenium for Plants. 2007.

22. HAMILTON S.J. Review of selenium toxicity in the aquatic food chain. Science of the Total Environment. 326 (1-3), 1, 2004.

23. SEPPÄNEN M.M., KONTTURI J., HERAS I.L., MADRID Y., CÁMARA C., HARTIKAINEN H. Agronomic biofortification of Brassica with selenium - enrichment of SeMet and its identification in Brassica seeds and meal. Plant \& Soil. 337 (1), 273, 2010.

24. CHILIMBA A.D.C., YOUNG S.D., BLACK C.R., MEACHAM M.C., LAMMEL J., BROADLEY M.R. Agronomic biofortification of maize with selenium (Se) in Malawi. Field Crops Research. 125 (1), 118, 2012.

25. ESRINGU A., USTA S., DURSUN A., ERCISLI S., YILDIRIM E. Selenium supplementation affects the growth, yield and selenium accumulation in lettuce (Lactuca sativa L.). Comptes rendus de l'Académie bulgare des Sciences. 68 (6), 801, 2015.

26. LIU Y., CHE F., WANG L., MENG R., ZHANG X., ZHAO $Z$. Fruit coloration and anthocyanin biosynthesis after bag removal in non-red and red apples (Malus $\times$ domestica Borkh.). Molecules. 18 (2), 1549, 2013.

27. SOUBEYRAND E., BASTEAU C., HILBERT G., LEEUWEN C.V., DELROT S., GOMÈS E. Nitrogen supply affects anthocyanin biosynthetic and regulatory genes in grapevine cv. Cabernet-Sauvignon berries. Phytochemistry. 103, 38, 2014.

28. AGUILAR-BARRAGÁN A., OCHOA-ALEJO N. Virusinduced silencing of MYB, and WD40, transcription factor genes affects the accumulation of anthocyanins in chilli pepper fruit. Biologia Plantarum. 58 (3), $567,2014$.

29. RAMSAY N.A., GLOVER B.J. MYB-bHLH-WD40 protein complex and the evolution of cellular diversity. Trends in Plant Science. 10 (2), 63, 2005.

30. YIN J.M., YAN R.X., ZHANG P.T., HAN X.Y., WANG L. Anthocyanin accumulation rate and the biosynthesis related gene expression in Dioscorea alata. Biologia Plantarum. 59 (2), 67, 2015

31. POVERO G., GONZALI S., BASSOLINO L., MAZZUCATO A., PERATA P. Transcriptional analysis in high-anthocyanin tomatoes reveals synergistic effect of Aft, and atv, genes. Journal of Plant Physiology. 168 (3), 270, 2011.

32. TSUDA T., YAMAGUCHI M., HONDA C., MORIGUCHI $\mathrm{T}$. Expression of anthocyanin biosynthesis genes in the skin of peach and nectarine fruit. Journal of the American Society for Horticultural Science American Society for Horticultural Science. 129 (6), 857, 2004. 